\title{
SYNTHESIS, CHARACTERIZATION AND COMPARISON OF SOME \\ CHELATE POLYMERS OF HYDRAZINE AND PHENYL HYDRAZINE WITH TRANSITION METAL IONS
}

\author{
S. Shrivastava ${ }^{1}$ and H. D. Juneja ${ }^{2}$ \\ 1 Department of Chemistry, Priyadarshini College of Engineering. \\ ${ }^{2}$ Department of Chemistry, PGTD Campus, RTMNU, Nagpur Univ. \\ E-mail : seemashrivastava@rediffmail.com
}

\begin{abstract}
Polymers are among the most complicated molecules known. Polymers are different from other molecules because the long chain characters allow the chains to become entangled in solution or in the solid state or for specific macromolecular structures to become lined up in regular arrays in the solid state.
\end{abstract}

\section{Introduction}

Several types of organic and inorganic polymers are reported (1-4). The special class of inorganic polymers in which co-ordination occurs between an organic group and a metal atom is known as coordination polymers(5). These polymers have properties both of inorganic and organic parts. The metallic part contributes towards thermal stability, electrical and thermal conductivity properties, whereas the organic portion is suppose to provide plasticity, toughness, and fabricability, necessary in many applications.Coordination polymers, i.e. polymers with inorganic elements in the back- bone have unique property profiles that make them different from organic polymers. Among the main features of coordination polymers are the following: -

- The number and variety of elements that are found in these polymers as a result of the relatively high abundance of inorganic elements in the earths crust,

- Strong bonds, which resist cleavage reactions,

- Multiple valances for attachment of a wide variety of ligands,

- High thermal stability, and, 
- The ability to tailoring new and interesting structures with endless variations. [6-9]

Much more research has been carried out with polymers in which the co ordinated metal atoms are copper, nickel and cobalt. Whereas oxygen atoms or carbon atoms adjacent to metal atoms provide the electrons required for coordinated bond. These polymeric materials show many potential uses with desirable chemical and physical properties such as Several applications as heterogeneous catalysts, separation of toxic and carcinogenic metal ions, water and soil remediation, semiconductors [10$17]$.

Present work includes the synthesis of thermally stable chelate polymers and their characterization including a detailed study of their structural aspects.

\section{Experimental}

Chemicals: All chemicals used were of A.R. grade

Instruments: EA 1108 Elemental Analyzer Carlo Erbus Instrument, CDRI, Luknow; UV-VIS-NIR Spectrophotometer make Perkin- Elmer Lambada 19; Nicholate Magna IR 550 Series 2, USA; Philips, X-Ray powder diffractometer; Thermogravimatric analyzer along with TADS computer system of Perkin- Elmer system.

Synthesis of chelate polymers:There are several possible methods of preparing metal coordination polymers; one of them includes the coordination of a metal ion by a preformed polymer containing chelating groups. Alternatively a poly dentate chelating ligand can be formed incorporating metal ions to form a linier macromolecule of (ML)ncomposition, which is adopted in present work.

Synthesis of ligands has been carried out in two steps, which are as follows;

Preparation of Dimethyl esters: Acids, dry methanol and concentrated sulfuric acids were mixed stochiometrically and refluxed, esters so 
formed were extracted in distilled, dry benzene and later benzene was distilled off to get pure ester. Following general reaction takes place.

$\mathrm{R}-(\mathrm{COOH})_{2}+2 \mathrm{CH}_{3} \mathrm{OH} \rightarrow \mathrm{R}-\left(\mathrm{COOH}_{3}\right)_{2}+2 \mathrm{H}_{2} \mathrm{O}$

Synthesis of ligands: preparation of Malonyl -bis-hydrazide and Malonyl -bis-phenylhydrazide obtained in first step, malonyl ester, methanol, hydrazine hydrate and in case of Malonyl -bis-phenylhydrazide, phenyl hydrazine were refluxed. Acid-bis hydrazide separated out as white crystalline solid. The solid were filtered, washed, recrystallized and characterized by elemental analysis, melting point and Infrared spectroscopy. The following reactionsare proposed;

$\mathrm{R}-\left(\mathrm{COOH}_{3}\right)_{2}+2 \mathrm{NH}_{2} \mathrm{NH}_{2} \rightarrow \mathrm{R}-\left(\mathrm{CONHNH}_{2}\right)_{2}+2 \mathrm{CH}_{3} \mathrm{OH}$

$\mathrm{R}-\left(\mathrm{COOH}_{3}\right)_{2}+2\langle\mathrm{O}\rangle \mathrm{NHNH}_{2} \rightarrow \mathrm{R}-(\mathrm{CONHNH}-\leadsto \mathrm{O})_{2}+2 \mathrm{CH}_{3} \mathrm{OH}$

Synthesisof chelate polymers: the polymers were prepared by taking the equimolar quantities of metal acetates and bis ligands in suitable solvent. For a series the conditions are almost same but to increase the yield and to overcome the solubility difficulties of the reactants, different interactions slightly modified methods are employed to synthesize the compounds. DMF was used as medium; the temperature of the reaction mixture was maintained at approximately $120^{\circ} \mathrm{C}$ to $150^{\circ} \mathrm{C}$. The colored product obtained with different transition metals was filtered, washed thoroughly and dried. The purity was ascertained by repeated washings, as the recrystallization is not possible due to insolubility.

The physical properties of all newly formed chelate polymers are given in table-1. Thecomposition of polymeric units for the chelate polymers formed were further confirmed by different techniques like elemental 
(Table-2), reflectance (Table-6), magnetic(Table-5), Thermogravimatric and infrared analysis.

\section{Results and discussion}

\section{Infrared studies}

Infrared spectrum is characteristic of the entire molecule. The coordination of a ligand to a metal ion introduces an additional atom into the vibrating system of the ligand. Due to this a change in the bond length, bond angle and an inter-atomic forces within the ligand is observed. IR- spectral assignment of the polymers of MBHH and MBPH are given in the table- $4 \& 5$.

The bands appearing at $1667 \mathrm{~cm}-1$ and $1664 \mathrm{~cm}-1$ in the case of $\mathrm{MBHH}$ and $\mathrm{MBPH}$ ligands respectively are assigned to $\mathrm{C}=\mathrm{O}$ group (18), which gets lowered down in the chelate polymers confirming that the Oxygen of $\mathrm{C}=\mathrm{O}$ taken part in the formation of chelating ring resulting into $-\mathrm{C}=\mathrm{O} \rightarrow \mathrm{M}$ Co-ordination bond (19). It has been found that bis-phenyl hydrazide undergo keto/enol tautomerism during polymerization. It has been supported by the fact that $\mathrm{C}=\mathrm{O}$ disappear and new bond observed around 1530 to $1555 \mathrm{~cm}-1$ in the IR spectra of polymers, which suggests that band of $\mathrm{C}=\mathrm{O}$ disappears due to the formation of $\mathrm{C}=\mathrm{N}$ as a result of enolization. This is further supported by the appearance of the $\mathrm{C}-\mathrm{O}$ band around $1100 \mathrm{~cm}-1$ in case of polymers. The bands appearing in the region 440-475cm-1 observed only in case of polymers are assigned to O$\mathrm{M}$, medium bands appear in the region $650-880 \mathrm{~cm}-1$ in some polymers, which may be assigned, to the co-coordinated water (19). A weak band appears in the region $420-450 \mathrm{~cm}-1$ that may be assigned to $\mathrm{M}-\mathrm{N}$ stretching vibration in polymers (19). 


\section{Magnetic susceptibility:}

Magnetic properties of the chelate polymers were studied for the elucidation of stereochemistry of central metal atom, which ultimately points out towards the geometry of the molecule.

Mn(II) $\mathrm{MBHH}$ and $\mathrm{Mn}(\mathrm{II}) \mathrm{MBPH}$ : the polymers of $\mathrm{Mn}(\mathrm{II})$ transition metal studied in the present work show the magnetic moment is 5.90 B.M. are reported in Table. From the values of magnetic moment it appears both the polymeric units have tetrahedral configuration.

$\mathrm{Co}(\mathrm{II}) \mathrm{MBHH}$ and $\mathrm{Co}(\mathrm{II}) \mathrm{MBPH}$ : the magnetic moment of $\mathrm{Co}(\mathrm{II})$ polymers at room temperature are experimentally found 4.91 and $4.80 \mathrm{~B}$. M. which shows the octahedral configuration (20).

Ni(II)MBHH and $\mathrm{Ni}(\mathrm{II}) \mathrm{MBPH}$ : these polymers have magnetic moment values are 3.93 and 3.86 B.M. indicating their stereochemistry to be high spin octahedral.

$\mathrm{Cu}(\mathrm{II}) \mathrm{MBHH}$ : the magnetic moment of $\mathrm{Cu}(\mathrm{II})$ polymer at room temperature is experimentally found 1.83 B. M. shows octahedral geometry.

\section{Electronic spectra of chelate polymers}

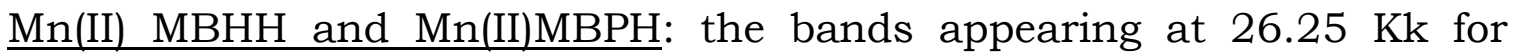
$\mathrm{Mn}(\mathrm{II}) \mathrm{MBHH}$ and $25.97 \mathrm{Kk} \mathrm{Mn}(\mathrm{II}) \mathrm{MBPH}$ are assigned to ${ }^{6} \mathrm{~A}_{1} \rightarrow{ }^{4} \mathrm{E}$ (D)transitions in tetrahedral field. The magnetic moment value also supports the tetrahedral geometry of these polymers.

$\mathrm{Co}(\mathrm{II}) \mathrm{MBHH}$ and $\mathrm{Co}(\mathrm{II}) \mathrm{MBPH}$ : in present study the band appearing between $19.23 \mathrm{Kk}$ to $18.86 \mathrm{Kk}$ in chelate polymers may be assigned due to ${ }^{4} \mathrm{~T}_{1 \mathrm{~g}} \rightarrow{ }^{4} \mathrm{~T}_{1 \mathrm{~g}}(\mathrm{P})$ transition in octahedral field (21). 



$\mathrm{Ni}(\mathrm{II}) \mathrm{MBHH}$ and $26.9 \mathrm{Kk}, 16.77 \mathrm{Kk}$ for $\mathrm{Ni}(\mathrm{II}) \mathrm{MBPH}$ may be assigned to ${ }^{3} \mathrm{~A}_{2 \mathrm{~g}} \rightarrow{ }^{3} \mathrm{~T}_{1 \mathrm{~g}}(\mathrm{P})$ and ${ }^{3} \mathrm{~A}_{2 \mathrm{~g}} \rightarrow{ }^{3} \mathrm{~T}_{1 \mathrm{~g}}$ transitions $(21)$. The absorption bands and tentative assignments are given in table- 5 .

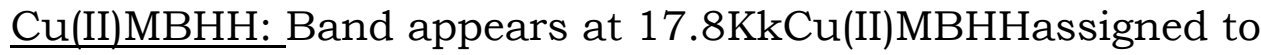

${ }^{2} \mathrm{~B}_{1 \mathrm{~g}} \rightarrow{ }^{2} \mathrm{E}_{\mathrm{g}}$ transition indicative of distortive octahedral.

\section{Thermo gravimetric analysis of chelate polymers}

The thermal behavior of various chelate polymers along with the kinetic parameters is studied in detail in earlier paper (22). The percentage mass loss for lattice water and coordinated water was calculated from the thermo gram. On the basis of these studies it has been found that Co(II) and $\mathrm{Ni}(\mathrm{II})$ polymers of $\mathrm{MBHH}$ and $\mathrm{MBPH}$ have two molecules of coordination water and no water of hydration

\section{Proposed structure of polymer}

Due to their high unreactibility and insolubility the characterization is difficult, however the elemental analysis has been carried out carefully and with the help of their magnetic and spectral properties the tentative structure may be proposed for these polymers. The similarities of IR spectra of all the poly chelates indicates that the mode of coordination of the ligands is same in all cases irrespective of metal atoms used except the number of water molecule attached. The stereochemistry of polymers and the oxidation state of central metal atom were confirmed by the magnetic and electronic studies. The results of all these studies are in good agreement with each other. Thus it has been suggested that Mn(II) $\mathrm{MBHH}$ and $\mathrm{Mn}(\mathrm{II}) \mathrm{MBPH}$ has tetrahedral geometry. Co(II) and Ni(II) MBHH and $\mathrm{MBPH}$ are octahedral geometry and $\mathrm{Cu}$ (II) $\mathrm{MBHH}$ has distorted 
octahedral geometry. The most tentative structures of the polymers are given below. Structure 1 Shows the representative Figure of Chelate polymer without coordinated water molecule where as structure 2 shows the the representative figure of Chelate polymer with coordinated water molecule.

\section{Proposed structure of Polymer}

\section{Structure: 1}

\section{M = Mn (II), Co (II), and Ni (II)}

m = Malonyl acid

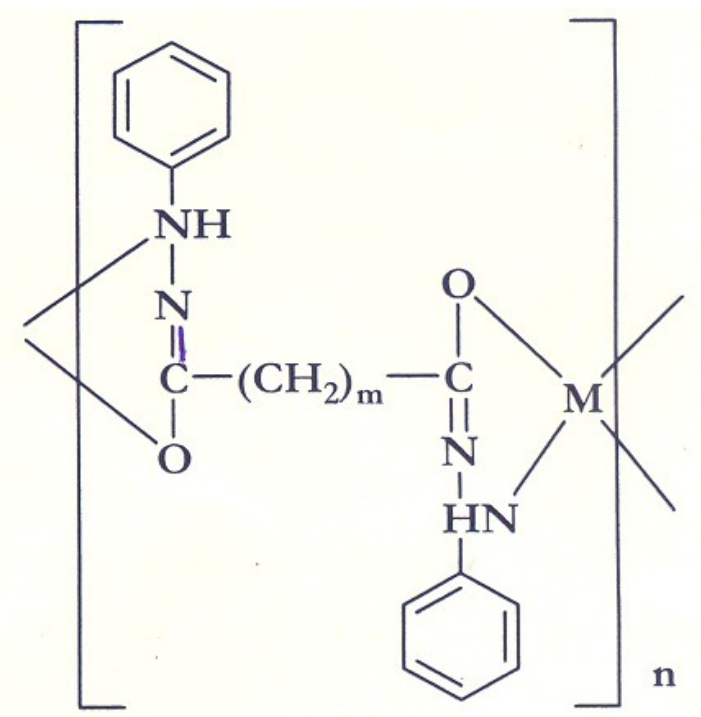

\section{Structure: 2}

$\mathbf{M}=\mathbf{C u}$ (II)

m = Malonyl acid

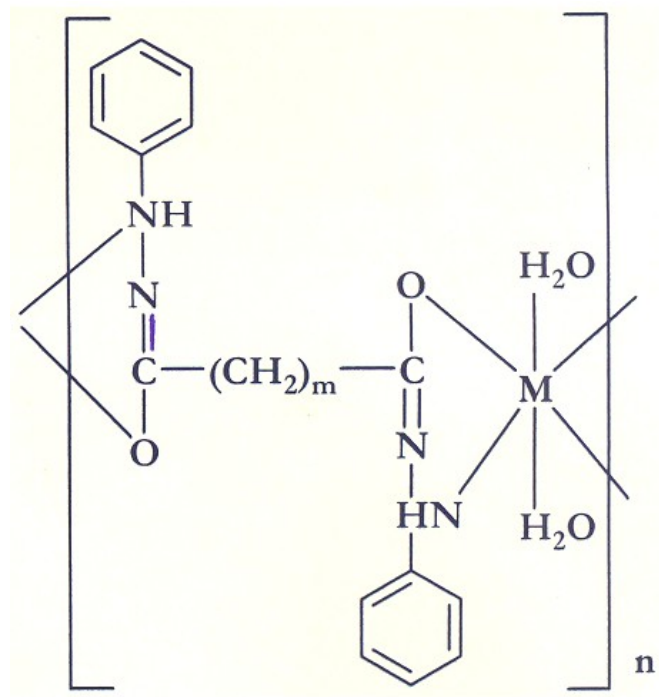


Table: 1

Physical properties: A comparative chart of the physical properties of different polymers

\begin{tabular}{|l|l|l|l|l|}
\hline $\begin{array}{l}\text { Proposed } \\
\text { Polymer }\end{array}$ & Color & Nature & Yield & $\begin{array}{l}\text { Decomp. } \\
\text { Temp. }\end{array}$ \\
\hline $\begin{array}{l}\text { Mn (II)mbhh } \\
\text { Mn (II)mbph }\end{array}$ & $\begin{array}{l}\text { Light Brown } \\
\text { Pale white }\end{array}$ & $\begin{array}{l}\text { Amorphous powder } \\
\text { Semi Crystalline }\end{array}$ & $\begin{array}{l}80 \% \\
50 \%\end{array}$ & $\begin{array}{l}370^{\circ} \mathrm{C} \\
320^{\circ} \mathrm{C}\end{array}$ \\
\hline $\begin{array}{l}\text { Co(II)mbhh } \\
\text { Co(II)mphh }\end{array}$ & $\begin{array}{l}\text { Purple } \\
\text { Light purple }\end{array}$ & $\begin{array}{l}\text { Amorphous powder } \\
\text { Amorphous powder }\end{array}$ & $\begin{array}{l}80 \% \\
50 \%\end{array}$ & $\begin{array}{l}300^{\circ} \mathrm{C} \\
3400^{\circ} \mathrm{C}\end{array}$ \\
\hline $\begin{array}{l}\text { Ni (II)mbhh } \\
\text { Ni(II)mbph }\end{array}$ & $\begin{array}{l}\text { Lirty Green } \\
\text { Light Green }\end{array}$ & $\begin{array}{l}\text { Amorphous powder } \\
\text { Amorphous powder }\end{array}$ & $\begin{array}{l}85 \% \\
50 \%\end{array}$ & $\begin{array}{l}380^{\circ} \mathrm{C} \\
350\end{array}$ \\
\hline
\end{tabular}

\section{Table:2}

Elemental analysis of chelate polymers:

Comparative elemental analysis of Malonyl-bis-Hydrazine hydrazide and Malonyl-bis-phenyl hydrazide

\begin{tabular}{|c|c|c|c|c|c|c|c|c|}
\hline \multirow{3}{*}{$\begin{array}{l}\text { Proposed polymeric } \\
\text { unit }\end{array}$} & \multicolumn{8}{|c|}{ Composition } \\
\hline & \multicolumn{4}{|c|}{ Theoretical } & \multicolumn{4}{|c|}{ Experimental } \\
\hline & $\% \mathrm{C}$ & $\% \mathrm{H}$ & $\% \mathrm{~N}$ & $\% \mathrm{M}$ & $\% \mathrm{C}$ & $\% \mathrm{H}$ & $\% \mathrm{~N}$ & $\% \mathrm{M}$ \\
\hline$[\mathrm{Mn}(\mathrm{II}) \mathrm{MBHH}] \mathrm{n}$ & 19.46 & 3.24 & 30.28 & 29.70 & 18.58 & 3.00 & 29.36 & 29.20 \\
\hline [Mn(II)MBPH]n & 53.42 & 4.15 & 16.62 & 16.30 & 52.88 & 4.67 & 16.12 & 15.78 \\
\hline $\begin{array}{l}{[\mathrm{Co}(\mathrm{II}) \mathrm{MBHH}} \\
\left.\left(2 \mathrm{H}_{2} \mathrm{O}\right)\right]_{\mathrm{n}}\end{array}$ & 16.00 & 4.44 & 24.89 & 26.19 & 15.92 & 4.34 & 24.80 & 26.15 \\
\hline $\begin{array}{l}{[\mathrm{Co}(\mathrm{II}) \mathrm{MBPH}} \\
\left.\left(2 \mathrm{H}_{2} \mathrm{O}\right)\right]_{\mathrm{n}}\end{array}$ & 47.75 & 4.77 & 14.85 & 15.63 & 47.10 & 4.22 & 14.35 & 14.99 \\
\hline$\left[\mathrm{Ni}(\mathrm{II}) \mathrm{MBHH}\left(2 \mathrm{H}_{2} \mathrm{O}\right)\right]_{\mathrm{n}}$ & 16.02 & 4.45 & 29.92 & 26.12 & 16.15 & 4.52 & 24.88 & 26.08 \\
\hline$\left[\mathrm{Ni}(\mathrm{II}) \mathrm{MBPH}\left(2 \mathrm{H}_{2} \mathrm{O}\right)\right]_{\mathrm{n}}$ & 49.16 & 4.60 & 14.33 & 14.90 & 48.68 & 4.23 & 15.12 & 15.50 \\
\hline$\left[\mathrm{Cu}(\mathrm{II}) \mathrm{MBHH}\left(2 \mathrm{H}_{2} \mathrm{O}\right)\right]_{\mathrm{n}}$ & 15.68 & 4.35 & 24.39 & 27.68 & 15.72 & 4.30 & 24.15 & 27.66 \\
\hline
\end{tabular}




\section{Table:3}

\section{Malonyl-bis-Hydrazine hydrazide Chelate Polymer-IR Spectroscopy}

\begin{tabular}{|l|l|l|l|l|}
\hline MBHH & Mn(II) & Co(II) & Ni(II) & Assignment \\
\hline 3305 & 3388 & 3361 & 3263 & $-\mathrm{NH} 2$ \\
\hline 1667 & ---- & ---- & ---- & $-\mathrm{C}=\mathrm{O}$ \\
\hline---- & 1559 & 1560 & 1560 & $-\mathrm{C}=\mathrm{N}$ \\
\hline 1530 & ---- & ---- & ---- & $-\mathrm{C}-\mathrm{N}$ \\
\hline---- & 1180 & 1173 & 1180 & $-\mathrm{C}-\mathrm{O}$ \\
\hline--- & ---- & 780 & 820 & H-OH(Co-ord) \\
\hline--- & 616 & 616 & 561 & M-O \\
\hline---- & 420 & 430 & 430 & M-N \\
\hline
\end{tabular}

\section{Table:4}

\section{MBPH Chelate Polymer-IR Spectroscopy}

\begin{tabular}{|l|l|l|l|l|}
\hline MBPH & $\mathrm{Mn}(\mathrm{II})$ & $\mathrm{Co}(\mathrm{II})$ & $\mathrm{Ni}(\mathrm{II})$ & Assignment \\
\hline & & & 3500 & H-OH(Lattice) \\
\hline 3326 & 3363 & 3433 & 3279 & $-\mathrm{NH} 2$ \\
\hline 1664 & ---- & ---- & --- & $-\mathrm{C}=\mathrm{O}$ \\
\hline---- & 1560 & 1561 & 1560 & $-\mathrm{C}=\mathrm{N}$ \\
\hline 1555 & ---- & ---- & ---- & $-\mathrm{C}-\mathrm{N}$ \\
\hline---- & 1035 & 1031 & 1168 & $-\mathrm{C}-\mathrm{O}$ \\
\hline---- & ---- & 810 & 792 & H-OH(Co-ord) \\
\hline---- & 617 & 616 & 664 & M-O \\
\hline---- & 489 & 450 & 420 & M-N \\
\hline
\end{tabular}

Table:5

Magnetic susceptibility: Comparison of magnetic susceptibilities of the polymers

\begin{tabular}{|l|l|l|l|l|l|}
\hline $\begin{array}{l}\text { Chelate } \\
\text { polymer }\end{array}$ & $\begin{array}{l}\text { Gram } \\
\text { susceptibility }\end{array}$ & $\begin{array}{l}\text { Atomic } \\
\text { susceptibility }\end{array}$ & $\begin{array}{l}\text { Corrected } \\
\text { Atomic } \\
\text { Susceptibility } \\
\mathrm{x}_{\mathrm{A}} \times 10^{-3}\end{array}$ & $\begin{array}{l}\text { Effective } \\
\text { magnetic } \\
\text { moment } \\
\text { B.M. }\end{array}$ & $\begin{array}{l}\text { Stereo } \\
\text { chemistry }\end{array}$ \\
\hline $\mathrm{Mn}(\mathrm{II}) \mathrm{MBHH}$ & 78.42 & 14.65 & 14.69 & 5.90 & Tetrahedral \\
\hline $\mathrm{Mn}(\mathrm{II}) \mathrm{MBPH}$ & 44.42 & 14.98 & 15.00 & 5.90 & Tetrahedral \\
\hline $\mathrm{Co}(\mathrm{II}) \mathrm{MBHH}$ & 44.49 & 10.09 & 10.14 & 4.91 & Octahedral \\
\hline $\mathrm{Co}(\mathrm{II}) \mathrm{MBPH}$ & 25.60 & 9.70 & 9.77 & 4.80 & Octahedral \\
\hline $\mathrm{Ni}(\mathrm{II}) \mathrm{MBHH}$ & 28.40 & 6.43 & 6.48 & 3.93 & Octahedral \\
\hline $\mathrm{Ni}(\mathrm{II}) \mathrm{MBPH}$ & 16.30 & 6.17 & 6.24 & 3.86 & Octahedral \\
\hline $\mathrm{CU}(\mathrm{II}) \mathrm{MBHH}$ & 5.89 & 1.36 & 1.40 & 1.83 & Octahedral \\
\hline
\end{tabular}




\section{Table:6}

Electronic spectra of chelate polymers: A comparative chart

\begin{tabular}{|l|l|l|l|}
\hline Chelate polymers & Kk & Assignment & Geometry \\
\hline $\mathrm{Mn}(\mathrm{II}) \mathrm{MBHH}$ & 26.25 & ${ }^{6} \mathrm{~A}_{1} \rightarrow{ }^{4} \mathrm{E}(\mathrm{D})$ & Tetrahedral \\
\hline $\mathrm{Mn}(\mathrm{II}) \mathrm{MBPH}$ & 25.97 & ${ }^{6} \mathrm{~A}_{1} \rightarrow{ }^{4} \mathrm{E}(\mathrm{D})$ & Tetrahedral \\
\hline $\mathrm{Co}(\mathrm{II}) \mathrm{MBHH}$ & 19.23 & ${ }^{4} \mathrm{~T}_{1 \mathrm{~g}} \rightarrow{ }^{4} \mathrm{~T}_{1 \mathrm{~g}}(\mathrm{P})$ & Octahedral \\
\hline $\mathrm{Co}(\mathrm{II}) \mathrm{MBPH}$ & 18.86 & ${ }^{4} \mathrm{~T}_{1 \mathrm{~g}} \rightarrow{ }^{4} \mathrm{~T}_{1 \mathrm{~g}}(\mathrm{P})$ & Octahedral \\
\hline $\mathrm{Ni}(\mathrm{II}) \mathrm{MBHH}$ & 20.07 & ${ }^{3} \mathrm{~A}_{2 \mathrm{~g}} \rightarrow{ }^{3} \mathrm{~T}_{1 \mathrm{~g}}(\mathrm{P})$ & Octahedral \\
& 13.9 & ${ }^{3} \mathrm{~A}_{2 \mathrm{~g}} \rightarrow{ }^{3} \mathrm{~T}_{1 \mathrm{~g}}$ & \\
\hline $\mathrm{Ni}(\mathrm{II}) \mathrm{MBPH}$ & 26.9 & ${ }^{3} \mathrm{~A}_{2 \mathrm{~g}} \rightarrow{ }^{3} \mathrm{~T}_{1 \mathrm{~g}}(\mathrm{P})$ & Octahedral \\
& 16.77 & ${ }^{3} \mathrm{~A}_{2 \mathrm{~g}} \rightarrow{ }^{3} \mathrm{~T}_{1 \mathrm{~g}}$ & \\
\hline $\mathrm{Cu}(\mathrm{II}) \mathrm{MBHH}$ & 17.8 & ${ }^{2} \mathrm{~B}_{1 \mathrm{~g}} \rightarrow{ }^{2} \mathrm{E}_{\mathrm{g}}$ & $\begin{array}{l}\text { Distorted } \\
\text { octahedral }\end{array}$ \\
\hline
\end{tabular}

\section{References:}

Kratz M.R. and Hendicker D-G. (1986). Polymer . 21, p .1941.

Moulton B, and Zaworotko M, (2001).J. Chem Rev;101:1629.

Janiak C. (2003). Dalton Trans:2781.86.

Robin AY, and Fromm KM. (2006). CoordChem Rev;250:2127.

P.Jeffrey Hay, Jack C. Thibeault, and Roald Hoffmann, (1975). J. Am. Chem. Soc., 97(17), 4884.

Kirk-Othmer, (1978). Encyclopedia of Chemical Technology, John Wiley, 398.

Allcock H.R., (1985). Developments at the Interface of Inorganic, Organic and Polymer Chemistry, C \& EN. March 18, 22.

Stevens M.P., (1990). Polymer Chemistry: An Introduction, 2nd ed., Oxford University, 487.

Rahimi A., (2004). Inorganic and organometallic polymers: A review, Iran. Polym. J., 13, 149-163.

So-Hye Cho; TendaiGadzikova; MitraAfshari; Sonbinh, 5.T.Nguyen; and Joseph T. Hupp; Eur. (2007). J. Inorg. Chem; pp. 4863-4867. 
Katerina, Kracalikova, and MiroslavBleha; (2008). Polymer Bulletin 61, 147-156.

Nicole E. Zander, (2009). Dynamic Sciebce, Inc, ARL-CR-0623.

Zallous, R. and Mubark, S.; (2008). Journal of Applied Polymer Science, 109, 3180-3184.

Spivakov, B.; Geckeler, K, and Bayer, (1988). E. Nature 315, 313-315.

Hashmal, J. A.; (1969). Avail Univ. Microfilm; Ann. Arbor, DissAbstr. Int,B30, 53-57.

Brawn, S. B.; (1977). Avail Univ. Microfilm; Ann. Arbor, DissAbstr. Int, $87,85295$.

Alan Heager J.; (2001). Material Research Society 26 (11), 900-904.

Silverstien, R.M.; (1961). "Spectrometric Identification of organic compounds" VthEdn. John Wiley.

Nakamoto K.; (1970). "Infrared spectra of Inorganic and coordination Compound" P. 167.

Nakamoto K.; (1970). "Infrared spectra of Inorganic and coordination Compound" P. 155.

Nicholis, D.; (1996). "Comprehensive Inorganic chemistry" 3, 979, 1053, 1109 (1973).22.Lee, J.D.; "Concise Inorganic Chemistry" 5thEdn. P 960.

Shrivastava S.A.; Ukey V.V. and Juneja H.D.; (2005). Chemistry an Indian Journal Vol. 12 p759-762. 